\title{
Effect of Different Doses of Vitamin A on $\beta$-HCG Production in Patients Suffering from Gestational Trophoblastic Disease
}

\author{
Shokoufeh Hosseini' $^{1 \text { (D), }}{\text { Masoumeh } \text { Yousefi }^{2} \text { (D), Maryam Ebrahimi*3 }}^{\text {iD }}$
}

1. Dept. of Statistics, Faculty of Mathematical Sciences, Alzahra University, Tehran, Iran

2. Dept. of Midwifery and Reproductive Health, Iran University of Medical Sciences, Tehran, Iran

3. Dept. of Obstetrics and Gynecology, Akbarabadi Hospital, Iran University of Medical of Sciences, Tehran, Iran

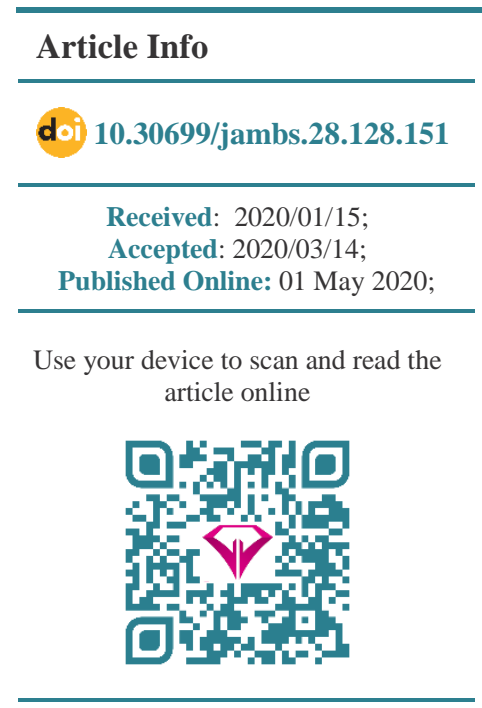

Corresponding Information:

Maryam Ebrahimi,

Dept. of Obstetrics and Gynecology, Akbarabadi Hospital, Iran University of Medical of Sciences, Tehran, Iran E-Mail:

Drmkhoddami@yahoo.com

\section{ABSTRACT}

Background \& Objective: Gestational trophoblastic disease (GTD) is a type of disease which is characterized by increased production of B-HCG by placental cells. Increased $\beta-\mathrm{HCG}$ production is due to increased proliferation of beta cells and lack of apoptosis. If left untreated, it can lead to malignancy. Almost 30-50 of GTD progresses to gestational trophoblastic neoplasia (GTN) in women over 40 years old. This study aimed to evaluate the effect of vitamin A doses $(100,000$ IU and 200,000 IU) on the decrement of $\beta$-HCG levels.

Materials \& Methods: The study included three groups: two patients and one control, and each group contained 22 individuals. Two groups of patients (A and B) received 100,000 IU and 200,000 IU doses of vitamin A, respectively, in addition to suction curettage. $\beta$-HCG levels were then measured by radioimmunoassay (RIA).

Results: The $\beta$-HCG drop-in group B, which received 200,000 IU of vitamin A, was higher than that of group A. It was significant in the third and fourth weeks after the treatment compared to the control group. There was also a significant relationship between the three groups in terms of Gravid $(P<0.001)$. All the patients were followed up for 6 months.

Conclusion: Considering that in the long run, the dose of 200,000 IU compared to the dose of 100,000 IU of vitamin A did not significantly reduce the B-HCG, therefore, in order to prevent the complications of high doses, the single dose of 100,000 IU was used for GTD patients.

Keywords: Gestational trophoblastic disease (GTD), $\beta-H C G$, Gravid, Parity, Vitamin A

Copyright $\odot$ 2020, This is an original open-access article distributed under the terms of the Creative Commons Attribution-noncommercial 4.0 International License which permits copy and redistribution of the material just in noncommercial usages with proper citation.

\section{Introduction}

The term gestational trophoblastic disease (GTD) is used to describe a group of disorders which are characterized by abnormal trophoblastic proliferation. Trophoblast produces human chorionic gonadotropin (HCG) hormone which is used for GTD diagnosis, treatment and monitoring $(1,2)$. Histologically, GTD is divided into hydatid-form moles (characterized by villi) and non-mole malignant neoplasms (without villi). Hydatid-form moles are actually immature placenta that are swollen extremely. Hydatid-form moles have two types: benign and malignant. The malignant type is characterized by invading $(3,4)$. The benign hydatid-form moles are divided into complete and incomplete moles according to the severity of histological changes, karyotype differences and presence of embryonic elements. Among the gestational trophoblastic neoplasia (GTN), the most frequent incidence is followed by the complete hydatid-form mole. Hydatid-form moles are diagnosed in about 1 per 1,000 deliveries in the United States
$(5,6)$. Age and previous history of moles are the risk factors which are associated with GTD. The preferred treatment is usually curettage suction, regardless of the uterus size and mole depletion (7). Careful biochemical monitoring of pre-pregnancy neoplasia is performed after discharge of the hydatid-form mole; this is done by serially measuring serum $\beta-H C G$ levels. Trophoblastic neoplasia examination is required during $\beta$-HCG monitoring if the B-HCG level is increased or constant and remains low. Metastatic GTN will occur in $4 \%$ of the patients with complete hydatid-form mole after tissue depletion. Cell proliferation and differentiation are controlled by the genes involved in the cell cycle; the apoptosis occurs when the repair process is damaged. Disruption of apoptosis results in the growth of cancer cells (8-10). The $p 53$ gene which is located on the short arm of chromosome 17 (17p13.1), plays a key role in tumor suppression by inducing apoptosis (11). Recently, patients' diet has been introduced as an important factor in the GTD 
development. Therefore, people with the diet that lacks the essential vitamins such as folate, $E$ and $A$ have been shown to be more susceptible to GTD $(\mathbf{1 2}, 13)$. Among these, vitamin A plays a key role in regulating the cell proliferation, differentiation and apoptosis via increasing p53 activity; it leads to cell cycle arrest at G1 stage and, ultimately, apoptosis. Using vitamin A will help prevent malignancy in the hydatid-form mole $(14,15)$. Rinojono reported that low levels of retinol in the blood of patients with hydatid-form moles led to retinoic acid decrement; it could cause uncontrolled proliferation of trophoblastic cells and reduce the apoptosis rate, which resulted in GTN progression. They concluded that vitamin A doses could prevent malignant changes (14). In this study, we investigated the effect of different doses of vitamin $A$ on the reduction with $\beta$-HCG production in the GTD patients.

\section{Materials and Methods}

\section{Patients and Control Selection}

The studied population was patients with molar pregnancy who referred to the hospitals affiliated with Iran University of Medical Sciences between 2018 and 2019. Patients' demographic information was extracted from their recorded files.
The inclusion criteria were as follows: gestational age below 12 weeks; no history of disease; $\beta$-HCG level $<100,000 \mathrm{IU}$; the age less than 40 years old; and having complete mole. The exclusion criteria included $\beta$-HCG level >100,000 IU and having incomplete mole. The 66 patients in the study were divided into three groups $(n=22)$. One group of patients received 100,000 IU of vitamin A, in addition to suction curettage. The second received 200,000 IU of vitamin $\mathrm{A}$ in addition to suction curettage. The third group was considered as the control; they only went under suction curettage without any vitamin intake.

The $\beta$-HCG was measured by radioimmunoassay (RIA). The measurement was done in all the three groups before the treatment and on the $4^{\text {th }}$ and $7^{\text {th }}$ days after the beginning of treatment. Then, it was measured weekly until the $\beta$-HCG level reached zero. After this step, it was measured in all three groups for 6 months. During the follow-up, some of the patients were excluded due to pregnancy and GTN.

The study was approved by the Ethics Committee of Iran University of Medical Sciences. Informed consent was obtained from all participants. Data were analyzed by SPSS 23 (SPSS Inc., Chicago, Ill., USA). Pvalue $<0.05$ was considered significant

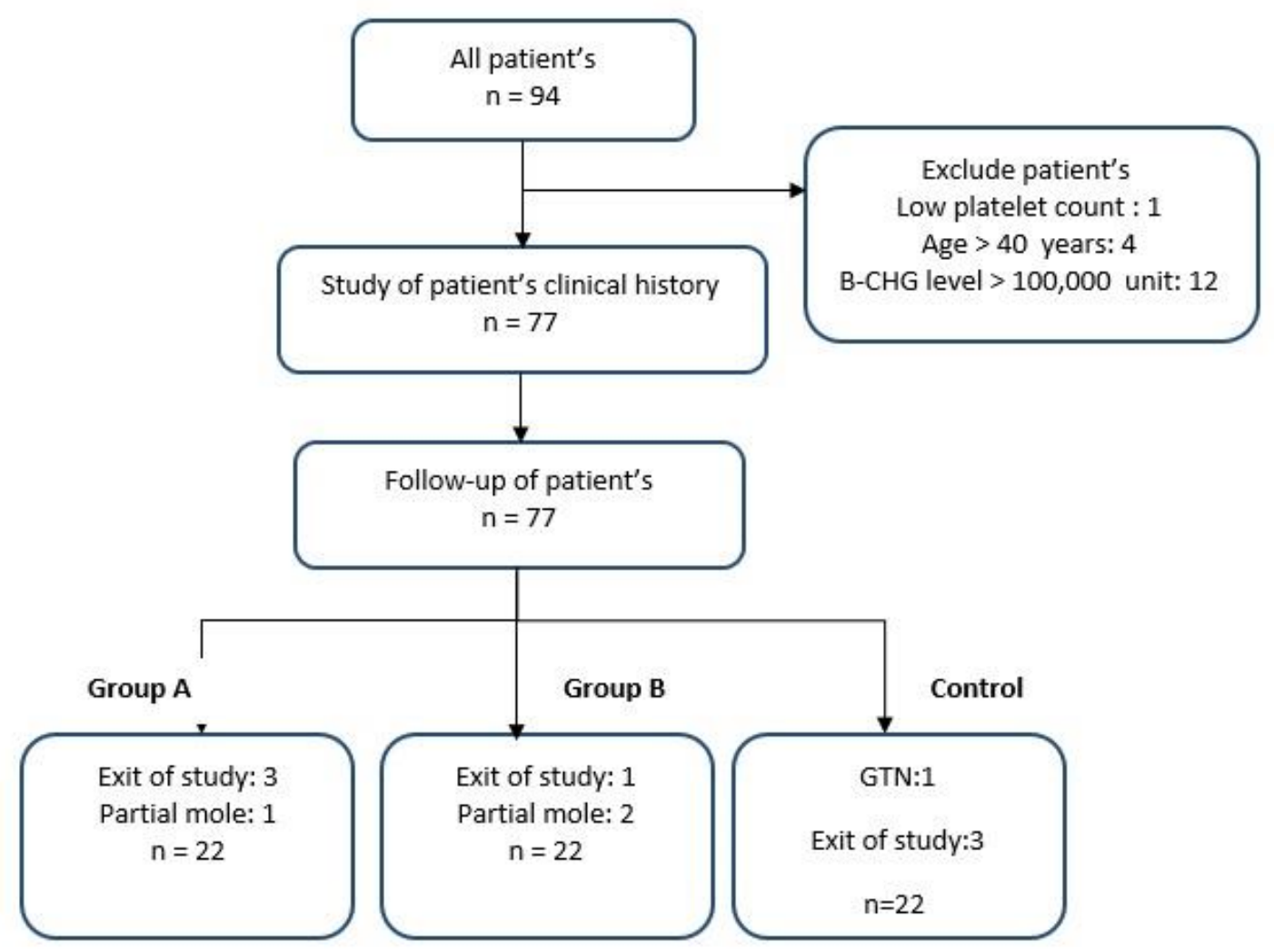

Figure 1. Resistance of $A$. baumannii and $P$. aeruginosa to antimicrobial drugs 


\section{Results}

After data collection (Table 1), a statistical analysis was conducted to evaluate the relationship between clinical parameters and effect of vitamin A on $\beta$-HCG level

\section{ß-HCG Level Assessment in 3 Groups During Follow-Up}

Therapeutic responses were evaluated by $\beta-\mathrm{HCG}$ titer in three groups. Prior to the treatment, $\beta$-HCG levels were $40600.3 \pm 27712$ in the control group compared to $51058.4 \pm 25751.9$ and $45165.7 \pm 27869.8$ in groups $\mathrm{A}$ and $\mathrm{B}$, respectively $(P=0.286)$. Four days after the treatment, it was $7686.5 \pm 6120$ in the control group and $3466.7 \pm 2958.8$ and $1917.8 \pm 1595.2$ in groups $\mathrm{A}$ and $\mathrm{B}$, respectively, which was statistically significant $(P<0.001)$.
One week after the treatment, the $\beta-\mathrm{HCG}$ level was $1537.6 \pm 1850.9$ in the control group and $334.2 \pm 197.4$ and $379.9 \pm 519.6$ in groups $A$ and $B$, respectively; there was a significant difference between the three groups $(P=0.029)$. On the $14^{\text {th }}$ day after the treatment, it was $471.9 \pm 803.5$ in the control group and $127.8 \pm 114$ and 92.4 \pm 93.4 in groups $A$ and $B$, respectively, which was not statistically significant $(P=0.143)$. It was111.3 \pm 209.1 in the control group three weeks after the treatment and $26.5 \pm 31.9$ and $19.4 \pm 32.6$ in groups A and $\mathrm{B}$, respectively, which was not statistically significant $(P=0.05)$. $\beta$-HCG levels were $33.5 \pm 53.1$ in the control group four weeks after the treatment and 0in groups $\mathrm{A}$ and $\mathrm{B}$, which was statistically significant $(P<0.001)$ (Table.1).

Table 1. Resistance of $A$. baumannii and $P$. aeruginosa to antimicrobial drugs.

\begin{tabular}{ccccc} 
Variable & Group A & Group B & Control & P-value \\
Age & $29.7 \pm 6.4$ & $29.1 \pm 6.2$ & $32.9 \pm 4.7$ & 0.07 \\
Parity (Range) & $0.5,3$ & 0,1 & $0.05,3$ & 0.17 \\
Gravid (Range) & 1,2 & 1,2 & $1.5,4$ & $<0.001$ \\
$\beta$-HCG, pre-treatment & $51058.4 \pm 25751.9$ & $45165.7 \pm 27869.8$ & $40600.3 \pm 27712$ & 0.286 \\
$\beta-H C G$, Four days after treatment & $3466.7 \pm 2958.8$ & $1917.8 \pm 1595.2$ & $7686.5 \pm 6120$ & $<0.001$ \\
$\beta$-HCG, One week after treatment & $334.2 \pm 197.4$ & $379.9 \pm 519.6$ & $1537.6 \pm 1850.9$ & 0.029 \\
\hline$\beta-H C G$, Two weeks after treatment & $127.8 \pm 114$ & $92.4 \pm 93.4$ & $471.9 \pm 803.5$ & 0.143 \\
$\beta-H C G$, Three weeks after treatment & $26.5 \pm 31.9$ & $19.4 \pm 32.6$ & $111.3 \pm 209.1$ & 0.052 \\
\hline$\beta-H C G$, Four weeks after treatment & 0 & 0 & $33.5 \pm 53.1$ & $<0.001$ \\
\hline
\end{tabular}

\section{Discussion}

Molar pregnancy is divided into two groups of complete and partial moles based on histological features and trophoblastic cell proliferation. The chance of complete mole progression to malignancy is $15-20 \%$ more than that of the partial mole (16-18). Vitamin A intake in association with chemotherapy drugs inhibits the proliferation of malignant cells $(\mathbf{1 9}, \mathbf{2 0})$. Recent papers have studied the effect of vitamin A on molar pregnancy and the association with clinical symptoms (21).

In a study by Andri et al., the effect of vitamin A on the progression of molar pregnancy was investigated. The results showed that vitamin A prevented disease progression. Also, there was no significant relationship between age as well asparity and the disease incidence (14). Kolusari et al. evaluated the levels of vitamins A and $\mathrm{E}$ and $\mathrm{D}$ in control individuals and molar pregnant patients. The results showed that the levels of these vitamins were reduced in the patients compared to the controls; the reduction of vitamins was associated with disease progression. Finally, it was concluded that increasing the amount of these vitamins in the patients could reduce the progression of molar pregnancy (22). In the current study, no statistically significance finding was obtained between age of the patients and controls $(P=0.07)$. In contrast to the significant relationship between the Gravid of three groups $(P<0.001)$, no significant relationship was found between their parity $(P=0.17)$. Bakhtyari et al. reported higher levels of $\beta$ HCG in the cases with advanced molar pregnancy in comparison to those at the early stage of the disease. It was also represented that elevated $\beta$-HCG levels can be associated with disease progression and reduced patient survival (23). 
The study by Ghasemian et al. also declared that using the 200,000IU dose of vitamin A with methotrexate reduced the GTD progression to GTN (24). In the present study, the results showed that the rate of $\beta$-HCG reduction was notable in the two groups of $\mathrm{A}$ and $\mathrm{B}$. Therefore, there was a significant relationship between the three groups in terms of $\beta-\mathrm{HCG}$ on the $1^{\text {st }}, 3^{\text {rd and }} 4^{\text {th }}$ days and four weeks after the treatment (Table 1).

\section{Conclusion}

Finally, it is concluded that at the beginning of the treatment, the single dose of 200,000 IU vitamin A compared to 100,000 IU can further reduce $\beta$-HCG levels in the patients. In the long run, there is no significant differences in comparison to the dose of 100,000 IU. Therefore, to prevent complications from high doses of the drug, the dose of 100,000 IU was used for GTD patients.

\section{Acknowledgments}

This article was the result of a research project conducted in the field of gynecology and obstetrics at Iran University of Medical Sciences.

\section{Funding}

This research did not receive any specific grant from funding agencies in the public, commercial, or not-forprofit sectors.

\section{Conflict of Interest}

Authors declared no conflict of interest.

\section{References}

1. Shaaban AM, Rezvani M, Haroun RR, et al. Gestational trophoblastic disease: clinical and imaging features. Radiographics. 2017;37(2):681700. [DOI:10.1148/rg.2017160140]

2. Ngan HY, Seckl MJ, Berkowitz RS, et al. Update on the diagnosis and management of gestational trophoblastic disease. Int J Gynecol Obstet. 2015;131:S123-S6.

[DOI:10.1016/j.ijgo.2015.06.008]

3. Usui H, Qu J, Sato A, et al. Gestational trophoblastic neoplasia from genetically confirmed hydatidiform moles: prospective observational cohort study. Int $\mathrm{J}$ Gynecol Cancer. 2018;28(9):1772-80. [DOI:10.1097/IGC.0000000000001374]
4. Niemann I, Vejerslev LO, Frøding L, et al. Gestational trophoblastic diseases-clinical guidelines for diagnosis, treatment, follow-up, and counselling. Dan Med J. 2015;62(11):A5082.

5. Lertkhachonsuk A, Hanvoravongchai P. Comparison of cost-effectiveness between actinomycin D versus methotrexate-folinic acid in the treatment of low-risk gestational trophoblastic neoplasia. J Rep Med. 2016;61(5-6):230-4.

6. Braga A, Maestá I, Matos M, Elias KM, Rizzo J, Viggiano MGC. Gestational trophoblastic neoplasia after spontaneous human chorionic gonadotropin normalization following molar pregnancy evacuation. Gynecol Oncol. 2015;139(2):283-7.

[DOI:10.1016/j.ygyno.2015.09.012]

7. Verit FF. May platelet count be a predictor of lowrisk persistent gestational trophoblastic disease? Arch Gynecol Obstet. 2011;283(4):695-9. [DOI:10.1007/s00404-010-1408-2]

8. Whitworth JM, Straughn JM, Atigadda VR, Muccio DD, Buchsbaum DJ. The use of retinoids in ovarian cancer: a review of the literature. Int $\mathrm{J}$ Gynecol Cancer. 2012;22(2):191-8. [DOI:10.1097/IGC.0b013e318236a2ec]

9. Sun P, Wu Q, Ruan G, et al. Expression patterns of maspin and mutant p53 are associated with the development of gestational trophoblastic neoplasia. Oncol Lett. 2016;12(5):3135-42. [DOI:10.3892/ol.2016.5074]

10. Zadeh FJ, Janatmakan F, Soltanzadeh M, Zamankhani M. Investigating the effect of fibrinogen injection on bleeding in coronary artery bypass surgery: A clinical trial. Anesthesiol Pain Med. 2019;9(4): e92165 [DOI:10.5812/aapm.92165]

11. Wu M, Zhang $\mathrm{H}, \mathrm{Hu} \mathrm{J}$, et al. Isoalantolactone inhibits UM-SCC-10A cell growth via cell cycle arrest and apoptosis induction. PloS one. 2013;8(9). [DOI:10.1371/journal.pone.0076000]

12. Kolusari A, Kurdoglu M, Yildizhan R, et al. Catalase activity, serum trace element and heavy metal concentrations, and vitamin $\mathrm{A}, \mathrm{D}$ and $\mathrm{E}$ levels in pre-eclampsia. J Int Med Res. 2008;36(6):1335-41. [DOI:10.1177/147323000803600622]

13. Al Riyami N, Al Riyami M, Al Thuriya Al Hajri SA, Saidi BS, Al Kalbani M. Gestational trophoblastic disease at Sultan Qaboos University Hospital: Prevalence, risk factors, histological features, sonographic findings, and outcomes. Oman Med J. 2019;34(3):200. [DOI:10.5001/omj.2019.39]

14. Andrijono A, Muhilal M. Prevention of post-mole malignant trophoblastic disease with vitamin A. Asian Pac J Cancer Prev. 2010;11(2):567-70. 
15. Zadeh FJ, Moadeli M, Soltanzadeh M, Janatmakan F. Effect of remote ischemic preconditioning on troponin I in CABG. Anesthesiol Pain Med. 2017;7(4). [DOI:10.5812/aapm.12549]

16. Cunningham FG, Leveno K, Bloom S, Hauth J, Gilstrap L, Wenstrom K. Gestational trophoblastic disease. Williams Obstetrics 22nd ed New York: McGraw Hill. 2005.

17. Stevens F, Katzorke N, Tempfer C, et al. Gestational trophoblastic disorders: an update in 2015. Geburtshilfe Frauenheilkunde. 2015;75(10):1043-50. [DOI:10.1055/s-00351558054]

18. Feizollahi N, Zayeri ZD, Moradi N, Zargar M, Rezaeeyan $\mathrm{H}$. The effect of coagulation factors polymorphisms on abortion. Front Biol. 2018;13(3):190-6. [DOI:10.1007/s11515-0181500-8]

19. Mazul AL, Weinberg CR, Engel SM, et al. Neuroblastoma in relation to joint effects of vitamin $\mathrm{A}$ and maternal and offspring variants in vitamin A-related genes: A report of the Children's Oncology Group. Cancer Epidemiol. 2019;61:16571. [DOI:10.1016/j.canep.2019.06.009]

20. Berkowitz RS, Cramer DW, Bernstein MR, Cassells S, Driscoll SG, Goldstein DP. Risk factors for complete molar pregnancy from a case-control study. AmJ Obstet Gynecol. 1985;152(8):1016-20. [DOI: $10.1016 / 0002-9378(85) 90550-2]$
21. Lawler S, Pickthall V, Fisher R, Povey S, Evans MW, Szulman A. Genetic studies of complete and partial hydatidiform moles. The Lancet. 1979;314(8142):580. [DOI:10.1016/S01406736(79)91632-5]

22. Kolusari A, Adali E, Kurdoglu M, Yildizhan R, Cebi A, Edirne T, et al. Catalase activity, serum trace element and heavy metal concentrations, vitamin $\mathrm{A}$, vitamin $\mathrm{D}$ and vitamin $\mathrm{E}$ levels in hydatidiform mole-Serum levels of catalase, $\mathrm{Zn}$, $\mathrm{Co}$, and vitamin $\mathrm{A}, \mathrm{D}$, and $\mathrm{E}$ were significantly lower in patients with hydatiform mole compared with healthy pregnant women and non pregnant controls. Clin Experiment Obstet Gynecol. 2009;36(2):102. [DOI:10.1177/147323000803600622]

23. Bakhtiyari M, Mirzamoradi M, Kimyaiee P, Aghaie A, Mansournia MA, Ashrafi-vand S, et al. Postmolar gestational trophoblastic neoplasia: beyond the traditional risk factors. Fertil Steril. 2015;104(3):649-54. [DOI:10.1016/j.fertnstert.2015.06.001]

24. Ghasemian S, Yousefi Z, Farazestanian M, Seresht LM, Foroughipour M, Akhlaghi S. Effect of combination therapy of methotrexate with vitamin A in patients with low risk GTN (Gestational Trophoblastic Neoplasia). IranJ Pharmaceut Res. 2018;17(Suppl):38.

\section{How to Cite This Article:}

Hosseini S, Yousefi Varazgaei M, Ebrahimi M. Effect of Different Doses of Vitamin A on $\beta$-HCG Production in Patients Suffering from Gestational Trophoblastic Disease. J Adv Med Biomed Res. 2020; 28 (128):151-155

Download citation:

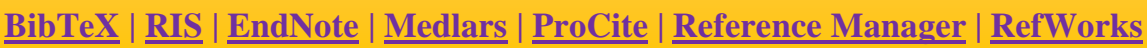

Send citation to:

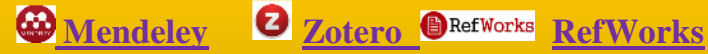

